\title{
Factors affecting energy expenditure
}

\section{By D. S. Miller, Queen Elizabeth College, London W8}

Sixteen years ago I presented a paper on this topic to this Society (Miller \& Mumford, 1966) and much of the subject matter was highly controversial: some might say it still is. However, it is my contention that if controversy exists today it is largely terminological, and therefore essential to define some of the terms used, such that any debate may be scientific rather than semantic. My earlier paper began with a traditional treatment of the first law of thermodynamics(I):

$$
\begin{gathered}
\Delta \text { Body energy }=\text { energy intake }- \text { energy expenditure } \\
\Delta \mathrm{B}=\mathrm{I}-\mathrm{E}
\end{gathered}
$$

In common with other authors at that time no units of measurement were indicated, despite the fact that it was common practice to measure intake as metabolizable energy but the other terms in gross energy; for human food the difference between gross and metabolizable energy was small (approximately $5 \%$ ) but with the current fashion for high-fibre diets the error would be greater. In those days energy expenditure was conceptually made up of the basal metabolic rate (BMR) plus physical activity (A) plus specific dynamic action (SDA):

$$
\mathrm{E}=\mathrm{BMR}+\mathrm{A}+\mathrm{SDA}
$$

Indeed the Food and Agriculture Organization (1957) computed (Equation 3, W, weight in $\mathrm{kg}$ ) the energy requirements of their reference man in terms of equation (2):

$$
\mathrm{E}=92 \mathrm{~W}^{\frac{3}{4}}+\mathrm{II} \mathrm{W}+0 \cdot \mathbf{I}
$$

However, in practice, the energy costs of physical activity were measured as gross values (i.e. including BMR and SDA) and these were listed in the superb tables of Passmore \& Durnin (1955) which have been widely used in time and motion studies to estimate energy expenditure. The net cost of physical activity (i.e. excluding BMR and SDA) was primarily the interest of exercise physiologists concerned with muscle metabolism, BMR that of clinicians concerned with thyroid disorders and SDA that of animal nutritionists producing fat stock. Much of this has changed and a more sensible way of looking at energy expenditure is given in Equation 4 :

$$
\text { Energy output }=\text { excreta }+ \text { work }+ \text { heat }
$$

It should be noted that work is the quantity of physical work performed on the external environment, since chemical work (e.g. the net cost of fat and protein synthesis), SDA, and even BMR will all appear as heat. Quantitatively the values for excreta and work are small, and a sedentary adult in our labour-saving society degrades almost all of his food energy to heat. If, in contrast to farm animals, he maintains weight for $5^{\circ}$ years, his existence may be seen as a tedious degradation 
of potential energy in a futile effort to warm the universe: to quote Lavoisier, life is indeed a combustion though it may burn brighter in some than in others. But a corollary is that intake is a fair approximation for expenditure. Conceptually it is conventional to consider this heat production to consist of two parts, BMR and other sources of heat:

$$
\text { Heat production }=\mathrm{BMR}+\text { thermogenesis }
$$

This methodology is not new to workers in animal nutrition who adopted it at the turn of the century (Armsby, 1903; Kellner, 1909). However, there are objective differences between human and animal experimentation that need to be respected. The human population has a wide genetic variation and our ability to construct experimental groups of similar individuals is severely limited. Statistically it is possible to reject outlying results, but philosophically we are interested in the performance of individuals. For example, the ability of a few individuals to maintain weight on intakes that differ two-fold is more fascinating than the mean intake of their group with its large standard deviation: the laws of thermodynamics must apply to them also. Examination of the literature on human energy expenditure reveals many contradictions. For example, some workers show that the obese have depressed metabolic rates whilst others show them to be normal. Both Roney (1940) and Garrow (1974), the main reviewers in this field, tabulate published results and attempt a 'ballot for truth', counting papers for or against various propositions. But it is difficult to believe that reputable workers in different laboratories are capable of making large experimental errors, and more likely that most of the results are valid at least for their subjects. It might be more profitable to study cases that deny preconceived ideas than to create unnecessary controversy.

\section{Work}

If the energy cost of physical activity is expressed as the more realistic increased value over the resting state, its contribution to daily energy expenditure is small. Certainly the occasional game of squash or weekend golf make an insignificant contribution, and even differences between occupations have been much reduced with labour-saving equipment. Work performed on the environment is smaller than the energy cost of working because the maximum efficiency of work is only about $25 \%$ : thus one might observe that the primary function of muscle is heat production. Nevertheless there are wide variations in the gross energy cost of simple activities. Table I shows values measured by an experienced investigator; the technical errors are of the order of $2 \%$ and the inter- and intra-individual variations represent true biological differences. The greatest range is shown for sitting, a frequent human activity; even army cadets spend more than half their time sitting (Edholm et al. 1970). The possibility that the efficiency of muscular work could be influenced by nutritional status has been investigated by Apfelbaum et al. (197I) who showed that the cost of walking and other activities can differ by $46 \%$ according to energy intake. This is consistent with our own findings that heat 
production following a meal is potentiated by exercise and has also been confirmed by Whipp (1975). Garrow's (1978) 'ballot for truth' in fact shows four 'for' and three 'against' and concludes that the effect in general is small, but I suggest that this factor is important in understanding both the inter- and intra-individual variations in the energy cost of standard tasks.

Table $\mathbf{I}$. Variability of the energy cost $(k \mathcal{f}(k c a l s) / m i n \pm$ coefficient of variation $C V)$ of sitting and standing

(All measurements made by one observer using a technique with a systematic error of less than $2 \%$ )

\begin{tabular}{|c|c|c|c|c|}
\hline \multirow[b]{2}{*}{ Subject } & \multicolumn{2}{|c|}{ Sitting } & \multicolumn{2}{|c|}{ Standing } \\
\hline & Mean & $\mathrm{CV} \%$ & Mean & $\mathrm{CV} \%$ \\
\hline 4 & $6 \cdot 4(\mathrm{I} \cdot 53)$ & 10 & $30 \cdot 5(7 \cdot 27)$ & 5 \\
\hline 5 & $6 \cdot 0(\mathrm{r} \cdot 43)$ & I3 & $29 \cdot 7(7.09)$ & 7 \\
\hline 6 & $7 \cdot \mathrm{I}(\mathrm{I} \cdot 6 \mathrm{~g})$ & 9 & $29.5(7.03)$ & 5 \\
\hline 9 & $6 \cdot 4(\mathrm{I} \cdot 53)$ & 7 & $3 \mathrm{I} \cdot 2(7 \cdot 43)$ & 7 \\
\hline IO & $7 \cdot 3(1 \cdot 74)$ & 5 & $32 \cdot 4(7 \cdot 71)$ & 4 \\
\hline 12 & $6 \cdot 5(1.55)$ & I 2 & $3 x \cdot 8\left(7 \cdot 5^{8}\right)$ & 6 \\
\hline
\end{tabular}

$B M R$

For most of us BMR accounts for about three-quarters of our daily energy expenditure. It may be predicted from weight, height, age and sex, and is often expressed in terms of surface area. However, when expressed in the same terms as food intake, i.e. /head per $d$, there can be marked differences between individuals. BMR is depressed in starvation (Keys et al. 1950) but the evidence that it is raised in overeating is equivocal. Differences between the lean and the obese have been denied but the classical work on BMR excluded the obese. Only some of the obese have a depressed BMR and we (Miller \& Parsonage, 1975) have identified a group of these. Volunteers were selected from slimming clubs on the basis they they could not lose weight on the diets prescribed. The subjects were incarcerated in an isolated country house, their luggage was searched and their car keys removed. They were fed under close supervision a diet providing only $6.3 \mathrm{MJ}$ ( $500 \mathrm{kcal}$ )/d for 3 weeks. Although nineteen subjects lost weight, nine maintained within $\pm \mathrm{I}$ kg, and two actually gained weight. There were good correlations between weight loss and energy expenditure, and those that maintained weight had low values for BMR. The group as a whole were $18 \%$ below Harris-Benedict standards (range +8 to $-47 \%$ ). Thus it is possible to be faced with two individuals of the same sex, age, height and occupation, one of whom is struggling to maintain body-weight by restricting energy intake to $6.3 \mathrm{~mJ}\left(\mathrm{I}_{5} 00 \mathrm{kcal}\right) / \mathrm{d}$ whilst the other can maintain it without trying.

\section{Thermogenesis}

Thermogenesis is that part of heat production unassociated with BMR. In our sedentary society it must account for most of the variations in energy expenditure between individuals. 
Isometric thermogenesis. This is usually referred to as isometric work but no work is done in the strict physical sense. The differences in energy expenditure between a man lying, sitting and standing are due to muscle tension: no work is being doing but heat is being produced. Similarly, if one compares a man and a table both supporting a large stationary weight, no work is being done in either case: the table does not require energy but the heat production of the man is considerable. From time to time it has been fashionable to use isometrics as a means of raising energy expenditure, particularly of sedentary workers whose occupation precludes physical activity. Frequent short bursts of muscular tension are recommended. It is certainly possible to treble oxygen consumption without moving by this method (see Table 2) but the perseverance required is considerable, and the effect on blood pressure is a possible contra-indication.

Table 2. Isometric work ( $k f(k c a l s) / m i n)$ : the energy cost of maintaining compression on a spring, with no work on the external environment

$\begin{array}{cccc}\begin{array}{c}\text { Spring tension } \\ (\mathrm{kg})\end{array} & \begin{array}{c}\text { Before } \\ \text { (resting) }\end{array} & \begin{array}{c}\text { Tension } \\ (\text { I } 0 \mathrm{~min})\end{array} & \begin{array}{c}\text { After } \\ (\mathrm{I} \mathrm{h})\end{array} \\ 3 & 4.5(\mathrm{I} \cdot 07) & 8.0(\mathrm{I} \cdot 90) & 4.8(\mathrm{I} \cdot \mathrm{I}) \\ 20 & 4.3(\mathrm{I} \cdot 02) & \text { II } \cdot 8(2.8 \mathrm{I}) & 5.5(1 \cdot 32)\end{array}$

Dynamic thermogenesis. The term 'negative work' is used by some physiologists to describe the heat production of stretched muscles. When a man climbs down a ladder heat production is increased: strictly he does no work, rather gravity is working on him. It would seem more appropriate to call this thermogenesis also. Thus in true physical work contracting muscles produce heat because of their inefficiency, whereas tensed and stretched muscles are simply thermogenic. How far muscular tissue contributes to thermogenesis is not known, but it cannot be negligible.

Cold-induced thermogenesis. It has been known for many years that man exposed to the cold increases his energy expenditure, though it is often claimed that cold-induced thermogenesis in man is rare because he seeks an equitable environment: but resting metabolic rates are known to be higher below thermoneutrality, a relatively high temperature $\left(27 \pm I^{\circ}\right)$. It is customary to distinguish between shivering and non-shivering thermogenesis (NST) but both have the same effect on heat production: the site of thermogenesis in the former is muscle, but the latter is associated with brown adipose tissue (BAT), at least in the newborn. In reviewing this subject Jessen (1980) reports a number of recent studies demonstrating the existence of NST in man. Evidence that BAT is important in adult man is sparse, but there seems to be more of this tissue than was originally thought (Heaton, 1972), and thermography indicates that it can be thermogenic (Rothwell \& Stock, 1979). Current interest in NST and BAT derives from the claim by Rothwell \& Stock (ibid.) that the tissue is also the site of dietary-induced thermogenesis. 
Dietary-induced thermogenesis. Heat production rises following the consumption of a meal, and is generally elevated on a high plane of nutrition. The former is classically termed specific dynamic action and the latter 'luxus konsumption'. The early literature is terminologically confused and this led to some heated controversies. More recently there has been a spate of papers published on the metabolic consequences of overeating and a general acceptance of the term dietary-induced thermogenesis (DIT). It is now clear that DIT is not specifically related to the protein content of the diet, that it increases with food consumption, and that it is potentiated with exercise and a frequent pattern of meal eating (Fabry, I 969). It is a metabolic response that tends to oppose the effects of fluctuations in food intake and which is more marked in the lean than in the obese. This work has been reviewed elsewhere (Miller, 1974, 1975a,b) but a few examples will illustrate the general conclusions. In our experiments on man (Miller \& Mumford, 1967), we have now overfed approximately forty-nine subjects. These have been given a variety of diets for periods up to 8 weeks. Their customary food intake was established previously and then each subject was encouraged to eat as much as possible above a minimum of $4.2 \mathrm{~mJ}$ (1000 kcal) extra/d. There was a marked weekly adaptation to the energy load, such that the rate of weight gain fell throughout the experiment. There was a marked individual variation, and it is quite remarkable how some individuals can eat an excess of $42 \mathrm{~mJ}$ (10000 kcal)/week and show a weight loss. Measurements of food digestibility, physical activity and body composition showed no significant change, but daily energy expenditure was increased.

The work has been confirmed in at least six laboratories (Kasper et al. 1973; Garrow, 1978), but there has been some contention, mainly from investigators whose experiments were either shorter or where the excess intakes were less. However, Norgan \& Durnin (1980) report no evidence for increased oxygen consumption during their 6 week overfeeding study although there was a discrepancy between weight gain and excess food consumed: these authors attribute this inconsistency to measurement and other unknown errors. Such arguments cannot however be applied to the marathon overfeeding study of Sims $\&$ Horton (1 968$)$, i.e. $42 \mathrm{~mJ}$ (10000 kcal)/d for $200 \mathrm{~d}$. Some subjects increased their weight by $20 \%$ whilst others gained little and with difficulty although they were consuming more food: the energy cost of maintenance was increased by all subjects. Overfeeding with diets of different composition indicates that those low in protein and high in carbohydrate favour thermogenesis, but that the effect of fat depends upon its composition (Kasper \& Plock, I971; Goldman et al. 1975). Kasper claims that maize oil is more thermogenic than olive oil. Overfeeding experiments on obese subjects have also been carried out by Bray (1972) who showed that those near maximum weight gained more slowly than those who had previously reduced weight, which might indicate a homoeostatic regulation of body-weight effected by changes in thermogenesis.

Drug-induced thermogenesis. There are three addictive drugs that are a normal part of our life, viz caffeine, alcohol and nicotine: all have been shown to be 
thermogenic. Pharmaceutical thermogenic agents have been known for a long time, e.g. thyroxine and dinitrophenol, but have many side effects. The field is one of active research at the present time because of its possible value in the treatment of obesity. We have been working with drugs (see Fig. I) known to stimulate the sympathetic nervous system (SNS), e.g. ephedrine, which increases energy expenditure as measured both by direct and indirect calorimetry (Evans \& Miller, 1977). Drugs that inhibit the SNS might also be effective in man.

Psychological thermogenesis. We are still largely ignorant of the influence of stress on heat production, to say nothing of love, anger, fear and excitement. The best evidence is given by Corey (1948) who showed that the energy expenditure of pilots increased when they were under air traffic control and that the rise was inversely related to their level of experience.

\section{Energy expenditure and weight maintenance}

During the last 20 years there has been much speculation on possible mechanisms to account for the regulation of body-weight and controls of both food intake and energy expenditure have been postulated. Although evidence of precise regulation over long periods of time (e.g. decades) is largely anecdotal, it is likely that some regulation cccurs if only because the amount of food consumed (e.g. tonnes/decade) is so much larger than body-weight. Correlations between energy intake and body-weight or body fat are low and sometimes negative, and appetite controls may be easily overridden by the skills of a good cook. It is difficult to believe that the primary control is of food intake, if only because of the wide variations in intake between similar individuals which show a two- to three-fold range. Widdowson ( 1962 ) has shown that for any twenty people of the same age, sex and occupation, one could be found to be eating twice as much as another, and Rose \& Williams (196I) studied large and small eaters with similar levels of activity whose intakes varied from 6.7 to $31 \cdot 1 \mathrm{~mJ}$ ( 1600 to $7400 \mathrm{kcal}) / \mathrm{d}$. Miller ( 1980 ) lists whole communities that live on very little food, and we (Table 3 ) have surveyed two communities of subsistence farmers in Iran and Ethiopia where food intakes are widely different yet anthropometric measurements are similar. Sims et al. (1973) demonstrated that the energy required to maintain weight by the

Table 3. Energy intakes and anthropometric measurements from surveys in Iran and Ethiopia

(Values show ratios between the two populations, i.e. Iran:Ethiopia. Measurements by the same team)

\begin{tabular}{|c|c|c|c|}
\hline & Energy intake & Weight & Triceps skinfold \\
\hline Adults $\sigma^{n}$ & I. 9 & $\mathbf{I} \cdot \mathbf{I}$ & 0.9 \\
\hline f & $1 \cdot 6$ & $\mathbf{I} \cdot \mathbf{I}$ & $I \cdot I$ \\
\hline 10-14 years $\sigma$ & $2 \cdot 3$ & 0.9 & 0.8 \\
\hline $5^{-9}$ years $\sigma^{\prime}$ & $2 \cdot 0$ & I $\cdot \mathbf{I}$ & $\mathrm{I} \cdot 2$ \\
\hline$q$ & I. 6 & 0.9 & $1 \cdot 2$ \\
\hline Mean & I. 8 & I. 0 & I.O \\
\hline
\end{tabular}


Stimulation

Destruction of $L$ nuclei e.g. stereotaxis?

Cholinomimetic e.g. nicotine

Inhibitors of ACh esterase e.g. parathion

Stimulators of noradrenaline release e.g. ephedrine, yohimbine
SNS

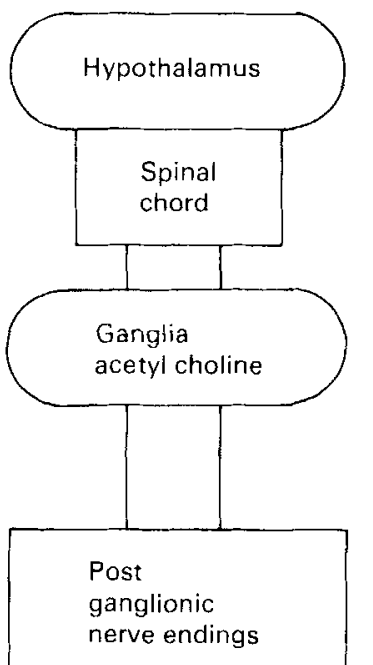

$\begin{aligned} & \text { Prevent release of noradrenaline } \\ & \text { noradrenaline }\end{aligned}$
$\begin{aligned} & \text { e.g.guanethidine, debrisoquine } \\ & \text { norake of }\end{aligned}$

e.g. amitriptyline

Inthibitors of MAO

e.g. tranylcypramine, iprindole

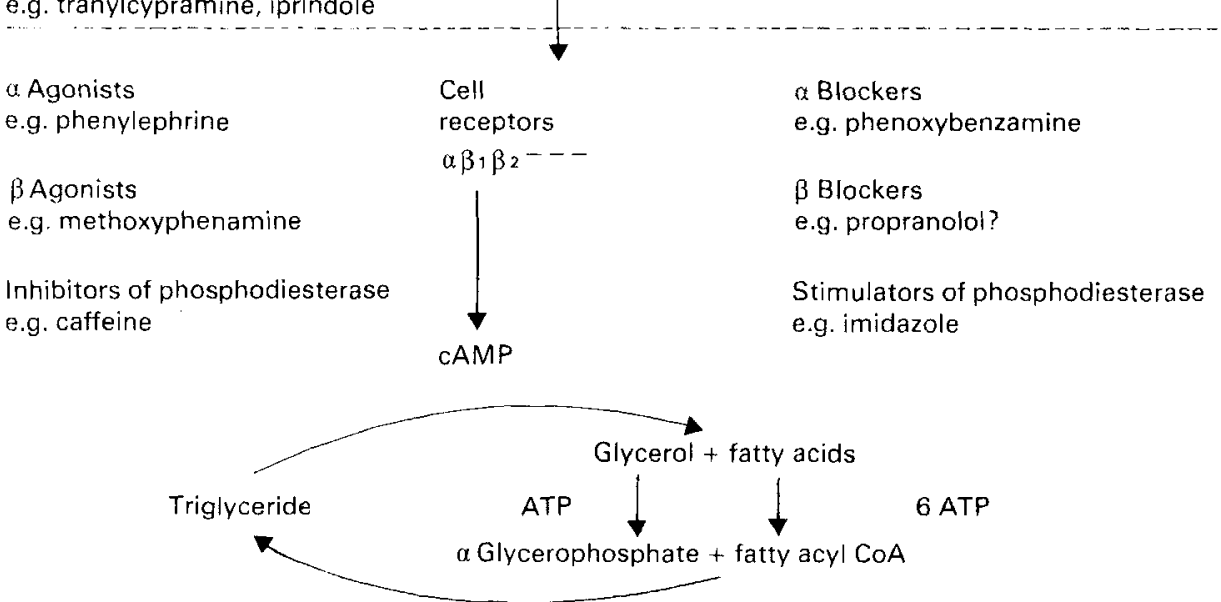

Fig. I. Schematic representation showing controls of energy balance mediated by the sympathetic nervous system (SNS). All the examples of stimulant drugs have been shown to increase metabolic rate. Obesity has been induced by drugs that lesion the hypothalamus and those that prevent the release of noradrenaline do promote weight gain but the evidence that other inhibitors of the SNS lower metabolic rate is equivocal. The futile cycle illustrated is only one of many possible: it requires $7 \mathrm{~mol}$ ATP per revolution i.e. per mol fat turned over. 
overfed was greater, and for hospitalized obese, less, than normal: the range for all their groups was two-fold.

The possibility that the observed variations in energy expenditure indicate a control of energy balance is tempting. Certainly DIT acts to oppose fluctuations in intake but this does not provide evidence for regulation. Those opposed to the concept of expenditure controls do not deny adaptations to undernutrition; nor do they deny DIT but seek to explain the rise in metabolic rate in terms of the energy cost of synthetic (fat and protein synthesis) or physical work (transport of additional weight), but these may still be regarded as adaptive changes. Even the most ardent supporters of 'luxus konsumption' would not claim that all overfed subjects maintain weight. Nor is it claimed that adaptation to changes in intake are unlimited: all obese subjects lose weight on $4.2 \mathrm{~mJ}$ (1000 kcal)/d and all lean subjects gain on $2.5 \mathrm{~mJ}(6000 \mathrm{kcal}) / \mathrm{d}$. Indeed most workers comment on large individual variation. The most convincing evidence comes from animal experiments: examples are the dogs of Grafe \& Graham (I II I), the pigs of Miller \& Payne (1962), the monkeys of Garrow and Stalley (Garrow, 1975), and some strains of rodents (Miller, 1979; Table 4); but for man it is necessary to select individuals from groups of subjects, a statistically suspect procedure. However, this brings us back to the problems of human experiments: if a predisposition to obesity or leanness is genetically determined as it is in animals, but undetectable in advance, it is inevitable that the literature on adaptation to energy intake will be contradictory. It is an individual and not a general phenomenon. To establish the role of thermogenesis in the regulation of energy balance to everyone's satisfaction it is surely only necessary to provide unimpeachable data on a single subject, but very precise measurements of heat production would be essential over a range of

Table 4. Efficiencies of some rodents (Miller, 1979)

(Gross energetic efficiency is the energy gain divided by the energy intake: for net energetic efficiency an allowance is subtracted from the intake to allow for the energy cost of maintenance, i.e. it is energy gain divided by the energy available for gain)

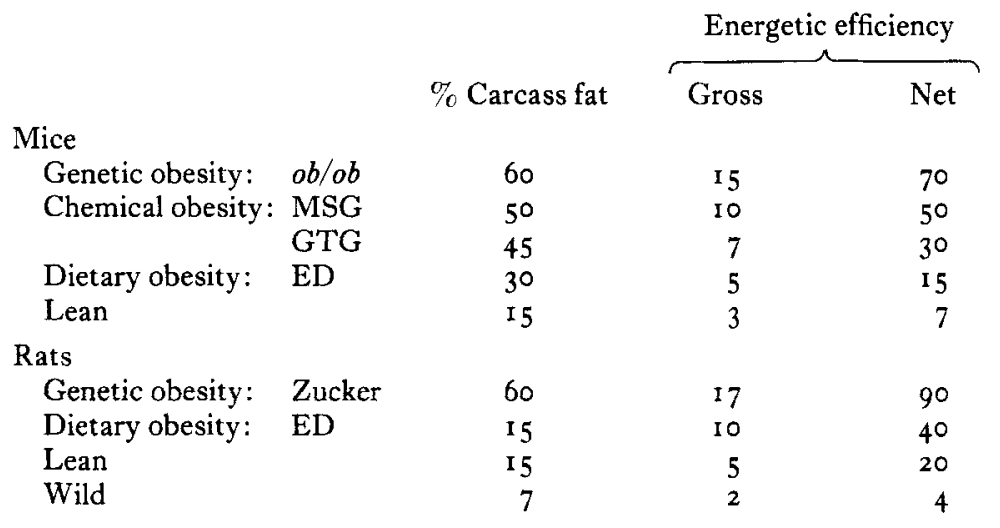

MSG, animals treated with monosodium glutamate in the first week of life. GTG, animals treated with gold thioglucose in the first week of life.

ED, animals fed an energy dense diet. 
intakes and for long periods of time, and to establish constant carcass composition it may be necessary to kill the subject before and after (sic) the experiment. But those of us who have been involved in overfeeding experiments or have conducted dietary surveys have been impressed by the wide variations in human response and do not doubt that some individuals show a remarkable adaptive ability: and those of you who have observed the food consumption of colleagues and friends must be aware that some of them have problems and others do not.

\section{REFERENCES}

Apfelbaum, M., Bostsarron, J. \& Lacatis, D. (197I). Am. F. clin. Nutr. 24, 1405 .

Arsmby, H. P. (1903). Principles of Animal Nutrition. New York.

Bray, G. A. (1972). F. clin. Invest. 51, 537.

Corey, E. L. (1948). F. appl. physiol. 1, 35 .

Edholm, O. G., Adam, J. M., Healy, M. J. R., Wolff, H. S., Goldsmith, R. \& Best, R. W. (1970). Br. Ұ. Nutr. 24, I09 1.

Evans, E. E. \& Miller, D. S. (1977). Proc. Nutr. Soc. 36, г 36 A.

Fabry, P. (1969). Feeding patterns and nutritional adaptations. London: Butterworth.

Food and Agriculture Organization (1957). FAO Nutritional Studies No. I 5. Rome: FAO.

Garrow, J. S. (1974). Energy Balance and Obesity in Man. New York: North Holland/Elsevier.

Garrow, J. S. (1975). In Regulation of Energy Balance in Man, p. 2 I 2 [E. Jequier, editor]. Geneva: Editions Medecine et Hygiene.

Garrow, J. S. (1978). In Recent Advances in Obesity Research II, p. 200 [G. A. Bray, editor]. London: Newman.

Goldman, R. F., Haisman, M. F., Bynum, G., Horton, E. S. \& Sims, E. A. H. (1975). In Experimental Obesity in Man, p. $16_{5}$ [G. A. Bray, editor]. Washington DC: US Govt Printing Office.

Grafe, E. \& Graham, D. (I9I I). Hoppe-Seyler's Z. physiol. Chem. 73, I.

Heaton, J. M. (1972). F. Anat. I 1 2, 35.

Jessen, K. (1980). Acta Anaesthesiol. Scand. 24, I38.

Kasper, H. \& Plock, E. (1971). Med. Klin. 66, 440.

Kasper, H., Thiel, H. \& Ehl, M. (1973). Am. F. clin. Nutr. 26, 197.

Kellner, O. (1 go9). The Scientific Feeding of Animals. Duckworth: London.

Keys, A., Brozek, J., Henschel, A., Mickelsen, O. \& Taylor, H. L. (1950). The Biology of Human Starvation. Minneapolis: University of Minneapolis Press.

Miller, D. S. (1974). Triangle 13, 5 I.

Miller, D. S. (1975a). In Obesity in Perspective, vol. 2 [G. A. Bray, editor]. Washington DC: US Govt Printing Office.

Miller, D. S. (1975b). In Regulation of Energy Balance in Man, p. 198 [E. Jequier, editor]. Geneva: Editions Medecine et Hygiene.

Miller, D. S. (1979). In Animal Models of Obesity, p. I 3 I [M. F. W. Festing, editor]. London: Macmillan.

Miller, D. S. (1980). In Food Chains and Human Nutrition [K. Blaxter, editor]. London: Applied Science.

Miller, D. S. \& Mumford, P. M. (1966). Proc. Nutr. Soc. 25, 100.

Miller, D. S. \& Mumford, P. M. (1967). Am. F. clin. Nutr. 20, 1212.

Miller, D. S. \& Parsonage, S. (1975). Lancet i, 773.

IMiller, D. S. \& Payne, P. R. (I 962). F. Nutr. 78, 255.

Norgan, N. G. \& Durnin, J. V. G. A. (1980). Am. F. clin. Nutr. 33, 978.

Passmore, R. \& Durnin, J. V. G. A. (1955). Physiol. Rev. 35, 801 .

Roney, H. R. (1940). Obesity छ Leanness. Philadelphia: Lea \& Febiger.

Rose, G. A. \& Williams, T. R. (196I). Br. F. Nutr, I5, I.

Rothwell, N. J. \& Stock, M. J. (1979). Nature, Lond. 281, 3 I.

Sims, E. A. H., Danforth, E., Horton, E. S., Bray, G. A., Glennon, J. A. \& Salans, L. B. (1973). Rec. Prog. Horm. Res. 29, 457. 
Sims, E. A. H. \& Horton, E. S. (1968). Am. F. clin. Nutr. 2 1, I455.

Whipp, B. J. (1975). In Obesity in Perspective, vol. 2 [G. A. Bray, editor]. Washington: US Govt Printing Office.

Widdowson, E. M. (1962). Proc. Nutr. Soc. 2 I, 121. 